Keywords: colorectal cancer; screening; repeat FOBT; social and geographical inequalities; deprivation; European Deprivation Index; general practitioner; multilevel analysis

\title{
Predictors of adherence to repeat fecal occult blood test in a population-based colorectal cancer screening program
}

\author{
C Pornet ${ }^{1}$, B Denis $^{2}$, P Perrin ${ }^{2}$, I Gendre ${ }^{2}$ and G Launoy ${ }^{\star, 1}$ \\ ${ }^{1}$ 'Cancers \& Preventions' INSERM U 1086, University of Caen Basse-Normandie, CHU, Caen France and ${ }^{2}$ Association pour le \\ dépistage du cancer colorectal en Alsace, 122 rue Logelbach, Colmar, France
}

Background: Socio-economic, environmental factors and general practitioner (GP) involvement may influence adherence to repeat faecal occult blood testing (FOBT) of organised colorectal cancer (CRC) screening. The aim of the study was to identify predictors of adherence to repeat testing.

Methods: The populationcomprised people eligible for the third round of a CRC screening programme in a French district $(n=118905)$. Multilevel logistic regression analysis was performed to identify individual and area-level characteristics associated with 'compliant participants' participating in the all three rounds vs 'occasional participants' participating in one or two rounds.

Results: Compared to 'occasional participants', 'compliant participants' were more likely to participate after receiving a FOBT kit from their GP (odds ratio (OR), 10.7; $95 \% \mathrm{Cl}, 10.01-11.5)$ vs FOBT received at home, and were less likely to live in socio-economically deprived areas (OR, 0.75; 0.70-0.80) and urban areas $(\mathrm{OR}, 0.94 ; 0.88-1.00)$.

Conclusions: As for a screening round participation, strategies aimed at improving the participation to a screening programme should target GPs and people living in socially deprived areas.

Although the determinants of initial participation in organised colorectal (CRC) screening programs are now known with welldocumented socio-economic disparities (von Wagner et al, 2009; Frederiksen et al, 2010; Pornet et al, 2010), little is known about the determinants of adherence to repeat screening, which is a critical component in faecal occult blood test (FOBT)-based screening programs. Serial adherence is crucial for screening efficacy (Gellad et al, 2011). Adherence to serial screening can boost programme sensitivity because cancers missed in round 1 (R1) can be detected in later rounds (Launoy et al, 1998).

There are no prior studies in Europe and only a few in the United States where, after first participation, very low $(24.6 \%-26.0 \%)$ or low (44.4\%) rates of adherence, respectively, of yearly (Gellad et al, 2011; Liss et al, 2013) and biennial (Fenton et al, 2010) repeat testing have been reported. The latter study showed that receiving a preventive health prevention examination was strongly associated with FOBT adherence relative to no CRC screening (adjusted relative rate ratio, 11.6; 95\% CI, 9.6-13.0). However, no studies to date have compared factors influencing complete-to-occasional adherence. Furthermore, no studies have used multilevel modelling, which takes into account the hierarchical data structure and is more suitable for investigating the impact on adherence to repeat screening of contextual effects such as socio-economic deprivation and rural/ urban residence.

This study investigated adherence to biennial FOBT in part of the French general population in an organised CRC screening programme. The objectives were to identify the proportion of people who completed repeat FOBT among people eligible for all the first three rounds, and to identify both individual and contextual factors associated with adherence to repeat screening. We also assessed which source of invitation, the visit to the GP and postal mailing of the FOBT kit was the most likely to influence adherence to repeat screening. 


\section{MATERIALS AND METHODS}

CRC screening programme. This retrospective study was conducted in the Haut-Rhin department in eastern France, with a population of around 750000 inhabitants, where the CRC screening programme was launched in September 2003 and lasted until September 2006 (R1). The two following rounds took place between September 2005 and September 2008 (R2), then between September 2007 and September 2010 (R3). The local screening programme centre mailed letters to all individuals aged 50-74 years. The letters recommended a visit to family GPs who explained the screening programme and test procedures and delivered a free FOBT kit if the person was considered at average risk of CRC. Individuals with serious illness, recent CRC screening or high CRC risk (symptoms, personal or family history of CRC, inflammatory bowel disease) were excluded. Nonrespondents received a first reminder within 3 months by mail explaining the need to visit their GP, and nonrespondents to this reminder received a second reminder within 3 months by mail with the FOBT kit and a prepaid return envelope. Participants in the screening programme performed the FOBT at home, then sent the kit to the screening programme laboratory, which sent the results to the participants, the GP and the local screening programme centre. People with positive FOBT results were referred by their GP to a gastroenterologist for a colonoscopy.

Study population. The target population was defined on the basis of health beneficiaries of the French statutory health insurance schemes, who represented $99.6 \%$ of the target population. The target population for the present study was all residents in HautRhin aged 50-74 years between September 2007 and September 2010 (R3).

The database from the local screening programme centre comprised 202171 persons eligible for R3 of CRC screening in Haut-Rhin (Figure 1). First, 1334 persons were excluded because they did not live at the address indicated. People ineligible for all the first three rounds were also excluded. Thus, 118905 persons were eligible for all the first three rounds.
Classification of individuals and outcomes. The study outcome was patient adherence to repeat screening. Adherence to repeat screening was defined by behaviour of eligible people during the first three rounds and was classified into three categories: 'never participants', 'compliant participants' who participated in all the first three rounds and 'occasional participants' who participated once (R3) or twice (R3 and (R1 or R2)).

To determine which source of invitation was the most associated with adherence to repeat screening, we excluded people who had performed the FOBT by means other than that proposed by the programme, and 'occasional participants' who did not participate in R3 because the source of invitation was known only to participants in R3. Finally, 61386 people were analysed.

Potential predictors of adherence to repeat screening. We considered potential predictors of adherence to repeat screening related to the individual (level 1) and to the area of residence (level 2).

Individual predictors (level 1) extracted from the screening programme database included gender, age, scheme of statutory health insurance and invitation sources that induced participation (those recommended in the French programme: GP and FOBT sent by mail).

Contextual factors (level 2) were related to the individual's ward of residence (i.e. area) as determined on the individual's exact address. In the absence of available individual socio-economic data, the socio-economic environment was assessed by using an aggregate deprivation index, the French version of the European Deprivation Index (EDI) (Pornet et al, 2012). The EDI was chosen because it is the first index whose score is available for all the smallest census units of the entire French mainland called 'Ilôt Regroupé pour l'Information Statistique' (IRIS) (maximum population 9618; mean population 2000). The study area, that is, 'Haut-Rhin' was constituted of 506 IRIS. Details for building method of IRIS and urban and rural areas are available on http:// www.insee.fr/fr/methodes). Moreover, EDI is reproducible over time and across Europe, thereby facilitating further European comparisons (Pornet et al, 2012). The EDI was uploaded with the 2007 national population census data and was categorised into quintiles with quintile 1 representing the least deprived and

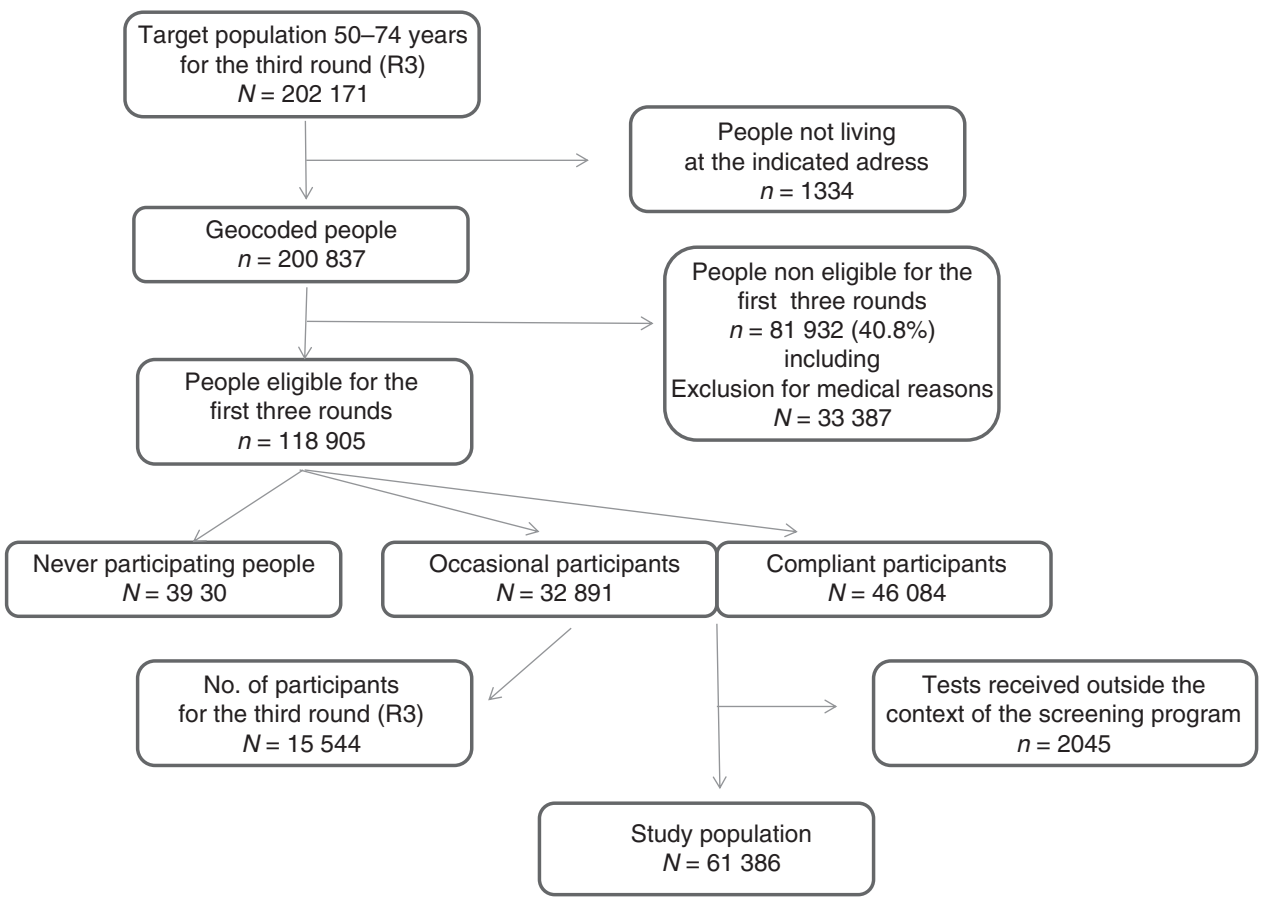

Figure 1. Flowchart. 
quintile 5 the most deprived areas. Each person was then assigned an EDI score and a rural/urban area status.

Statistical analysis. Analyses were performed with SAS version 9.3 (Statistical Analysis System software, version 9.3, Cary, NC, USA).

The influence of aggregate data and individual data on adherence to repeat screening ('occasional participants' $v s$ 'compliant participants'), was analysed, firstly using univariate logistic regression, then two-level (multilevel) logistic regression models with individuals (level 1) residing within the areas (level 2). The adopted modelling strategy consisted of increasing model complexity at each step, using a random intercept model (Pornet et al, 2010).

\section{RESULTS}

Study population. Among the 118905 persons eligible for the three first rounds, $33.6 \%$ persons were 'never participants', $27.7 \%$ 'occasional participants' and 38.8\% 'compliant participants' (Figure 1). Characteristics of the three categories of participants are described in Supplementary Table 1.

Factors associated with adherence to repeat testing. By the univariate model, being a man, in the youngest age group, a selfemployed person, performing the FOBT after receiving it at home and living in the most deprived and in urban areas were significantly and positively associated with 'occasional' adherence to repeat testing (data not shown).

Adherence to repeat screening varied significantly across the areas $(P<0.0001$, test of random intercept) (Supplementary Table 2, empty model). All individual factors significantly associated with adherence to repeat testing in the univariate model remained significant and were independently influent (model 1). The highest adjusted odds ratio (ORa) of 'compliant participants' (10.7; 95\% CI, 10.01-11.5) was associated with participation in R3 following a GP visit. Adding EDI to individual factors showed that 'occasional participants' were more likely to live in the most deprived areas (ORa, 0.73; 95\% CI, 0.69-0.78; model 2) than 'compliant participants', and adding rural/urban context showed that 'occasional participants' were more likely to live in urban areas (ORa, 0.85; 95\% CI, 0.81-0.90; model 3). The full model (Table 1 and Supplementary Table 2, model 4) did not decrease the variability across the areas compared with model 2 including EDI and the influence of EDI remained as significant (ORa, 0.75; 95\% CI, 0.70-0.80) as without rural/urban adjustment. In other words, rural/urban context shows a very weak association with adherence to repeat testing, unlike socio-economic context.

\section{DISCUSSION}

A low rate of adherence to repeat FOBT was found as only a little more than one-third of eligible persons were 'compliant' participants. The family GP was the main source of invitation for 'compliant' participants whereas FOBT mailing was strongly associated with 'occasional' participation. Socio-demographic characteristics and socio-economic environment also influenced adherence, but to a lesser extent, with the youngest age-group people, men, people insured by health coverage schemes for the self-employed and people living in the most deprived areas being the participants least likely to be 'compliant'.

Our overall compliance with repeat FOBT in the general population is intermediate between two US rates, that is, $44.0 \%$ in a private integrated health plan and delivery system (Fenton et al, 2010 ) and $24.6 \%$ in an urban community health centre network (Liss et al, 2013).
Table 1. Multivariable multilevel logistic regression of factors associated with adherence to repeat testing in the CRC screening programme (i.e., 'compliant participants' vs 'occasional participants', Haut-Rhin, France 2007-2010, $n=61386$ )

\begin{tabular}{|c|c|c|c|}
\hline & \multicolumn{3}{|c|}{ Full multilevel model } \\
\hline & $\begin{array}{l}\text { Empty } \\
\text { model }\end{array}$ & ORa $(95 \% \mathrm{Cl})$ & $P$-value ${ }^{a}$ \\
\hline \multicolumn{4}{|l|}{ Fixed effects } \\
\hline $\begin{array}{l}\text { Level 1: individual } \\
\text { Gender } \\
\text { Women } \\
\text { Men }\end{array}$ & & $\begin{array}{c}1.00 \\
0.90(0.86-0.94)\end{array}$ & 0.0001 \\
\hline $\begin{array}{l}\text { Age (years) } \\
50-54 \\
55-59 \\
60-64 \\
65-69 \\
70-74\end{array}$ & & $\begin{array}{c}1.00 \\
1.32(1.23-1.43) \\
1.58(1.46-1.71) \\
1.75(1.61-1.90) \\
1.95(1.79-2.13)\end{array}$ & $<0.0001$ \\
\hline $\begin{array}{l}\text { Health insurance plan } \\
\text { General plan } \\
\text { Self-employed plan } \\
\text { Agricultural plan } \\
\text { Special plan } \\
\text { Civil service plan }\end{array}$ & & $\begin{array}{c}1.00 \\
0.85(0.76-0.95) \\
1.05(0.95-1.17) \\
1.43(1.27-1.60) \\
1.21(1.13-1.30)\end{array}$ & $<0.0001$ \\
\hline $\begin{array}{l}\text { Source of invitation } \\
\text { Mail } \\
\text { General practitioner }\end{array}$ & & $\begin{array}{c}1.00 \\
10.73(10.01-11.50)\end{array}$ & $<0.0001$ \\
\hline $\begin{array}{l}\text { Level 2: area } \\
\text { EDI (deprivation index) } \\
\text { Quintile } 1 \text { (least deprived) } \\
\text { Quintile } 2 \\
\text { Quintile } 3 \\
\text { Quintile } 4 \\
\text { Quintile } 5 \text { (most deprived) }\end{array}$ & & $\begin{array}{c}1.00 \\
1.05(0.98-1.12) \\
1.00(0.93-1.08) \\
1.04(0.96-1.13) \\
0.75(0.70-0.80)\end{array}$ & $<0.0001$ \\
\hline $\begin{array}{l}\text { Rural/urban areas } \\
\text { Rural } \\
\text { Urban }\end{array}$ & & $\begin{array}{c}1.00 \\
0.94(0.88-1.00)\end{array}$ & 0.0409 \\
\hline \multicolumn{4}{|l|}{ Random effects } \\
\hline Level 2 variance (s.e.) & $0.2709(0.0559)$ & $0.1133(0.036$ & 66) \\
\hline
\end{tabular}

Our finding of the strong association between GP and compliance is inconsistent with the longitudinal US study, in which relative adherence with FOBT was significantly but slightly associated with a large number of primary care visits, whereas receiving a preventive health examination was strongly associated with FOBT adherence relative to no CRC screening. However, comparison of the role of practitioners in organised and opportunistic screening programmes has strong limitations. The relationship between compliance and GP highlighted in our study may also reflect a selection bias and may be related more closely to patient characteristics than to GP inducement. By contrast, this present finding strengthens the positive major role for GPs in patient adherence to the screening process, from initial participation to colonoscopy after a positive FOBT (Federici et al, 2006; Ferrat et al, 2013).

Socio-demographic factors of the lower adherence are consistent with previous European and US findings regarding initial participation for colorectal cancer screening (Wee et al, 2005; Weber et al, 2008; Pornet et al, 2010; Leuraud et al, 2013) as well as with repeat mammography use (Dailey et al 2011). Similarly, socio-economic environment influenced initial participation in such a way that areas of weak participation were linked to areas of strong deprivation (von Wagner et al, 2009; Pornet et al, 2010; Le Breton et al, 2012). It is worth noting that the strongest 
determinant of a repeated adherence screening is the involvement of GPs and that their key role is not affected at all by the socioeconomic environment of their patients or the type of rural/urban residence. The main strength of our study is the inclusion of socioeconomic environment in a multilevel analysis in a real world population-based programme. Other strengths include its largescale and long duration. Finally, our geocoding tool enables us to draw detailed maps of repeat uptake rates that will help healthcare policymakers to ensure better targeting of further interventions to enhance adherence to repeat testing.

As uptake related to direct mailing of FOBT kits is low, postal contact is being abandoned in France. Further research is needed to assess the savings made, which could be allocated to increasing GP involvement and establishing recommendations that might have a higher impact on compliance (Federici et al, 2006; Senore et al, 2010). Additional socio-economic disparities in repeated adherence compound the already well-documented ones regarding initial participation. A substantial effort particularly targeting GPs is needed to increase uptake and adherence to repeat testing and to reduce social and geographical inequalities in France.

\section{ACKNOWLEDGEMENTS}

We thank the GPs of the Haut-Rhin for their active participation in this programme, all the staff at ADECA Alsace (Association pour le dépistage du cancer colorectal en Alsace) and the participating gastroenterologists and pathologists for their contributions. They also thank the Centre Maurice Halbwachs and EUROSTAT for providing French census data and EU-SILC survey data, respectively, for computing the EDI.

\section{CONFLICT OF INTEREST}

The authors declare no conflict of interest.

\section{REFERENCES}

Dailey AB, Brumback BA, Livingston MD, Jones BA, Curbow BA, Xiaohui X (2011) Area-level socioeconomic position and repeat mammography screening use: results from the 2005 national health interview survey. Cancer Epidemiol Biomarkers Prev 20(11): 2331-2344.

Federici A, Giorgi Rossi P, Bartolozzi F, Farchi S, Borgia P, Guastcchi G (2006) The role of GPs in increasing compliance to colorectal cancer screening: a randomised controlled trial (Italy). Cancer Causes Control 17: 45-52.

Fenton JJ, Elmore JG, Buist DSM, Reid RJ, Tancredi DJ, Baldwin LM (2010) Longitudinal adherence with fecal occult blood test screening in community practice. Ann Fam Med 8: 397-401.
Ferrat E, Le Breeton J, Veerbudun K, Bercier S, Brixi Z, Khoshnood B, Paillaud E, Attali C, Bastuji-Garin S (2013) Colorectal cancer screening: factors associated with colonoscopy after a positive faecal occult blood test. Br J Cancer 109: 1437-1444.

Frederiksen BL, JØrgensen T, Brasso K, Holten I, Osler M (2010) Socioeconomic position and participation in colorectal cancer screening. Br J Cancer 103: 1496-1501.

Gellad ZF, Stechuchak KM, Fisher DA, Olsen MK, McDuffie JR, Ostbye T, Yancy Jr WS (2011) Longitudinal adherence to fecal occult blood testing impacts colorectal cancer screening quality. Am J Gastroenterol 106: 1125-1134.

Launoy G, Duffy SW, Prevost TC, Bouvier V (1998) [Detection of cancer, sensitivity of the test and sensitivity of the screening program]. Rev Epidemiol Santé Publique 46: 420-426.

Le Breton J, Journy N, Attali C, Le Corvoisiser P, Brixi Z, Bastuji-Garin S, Chevreul K (2012) Improving participation for colorectal cancer screening. Targets for action. Prev Med 55: 488-492.

Leuraud K, Jezewski-Serra D, Viguier J, Salines E (2013) Colorectal cancer screening by guaiac occult blood test in France: evaluation of the programme two years after launching. Cancer Epidemiol 37: 959-967.

Liss DT, Petit-Homme A, Feinglass J, Buchanan DR, Baker DW (2013) Adherence to repeat fecal occult blood testing in an urban community health center network. J Community Health 38: 829-833.

Pornet C, Dejardin O, Morlais F, Bouvier V, Launoy G (2010) Socioeconomic determinants for compliance to colorectal cancer screening. A multilevel analysis. J Epidemiol Community Health 64: 318-324.

Pornet C, Delpierre C, Dejardin O, Grosclaude P, Launay L, Guittet Lang T, Launoy G (2012) Construction of an adaptable European transnational ecological deprivation index: the French version. J Epidemiol Community Health 66: 982-989.

Senore C, Armaroli P, Silvani M, Andreoni B, Bisanti L, Marai L, Castiglione G, Grazzini G, Taddei S, Gasperoni S, Giuliani O, Malfitana G, Marutti A, Genta G, Segnan N (2010) Comparing different strategies for colorectal cancer screening in Italy: predictors of patients' participation. Am J Gastroenterol 105: 188-198.

von Wagner C, Good A, Wright D, Rachet B, Obichere A, Bloom S, Wardle J (2009) Inequalities in colorectal screening participation in the first round of the national screening programme in England. $\mathrm{Br} J$ Cancer 101(Suppl 2): S60-S63.

Weber MF, Banks E, Ward R, Sitas F (2008) Population characteristics related to colorectal cancer testing in New South Wales, Australia: results from the 45 and up Study Cohort. J Med Screen 15: $137-142$.

Wee CC, McCarthy EP, Phillips RS (2005) Factors associated with colon cancer screening: the role of patient factors and physician counseling. Prev Med 41: 23-29.

This work is published under the standard license to publish agreement. After 12 months the work will become freely available and the license terms will switch to a Creative Commons AttributionNonCommercial-Share Alike 3.0 Unported License.

Supplementary Information accompanies this paper on British Journal of Cancer website (http://www.nature.com/bjc) 